\title{
LIBERALISMO Y DEMOCRACIA
}

CORINA YTURBE

INSTITUTO DE InVESTIGACIONES FILOSÓFICAS

UNAM

La existencia de los regímenes liberal-democráticos o de democracia liberal induce a creer, señala Norberto Bobbio en su libro Liberalismo y democracia, que liberalismo y democracia son interdependientes. En su defensa de la democracia como tal, Bobbio no ha abandonado jamás el liberalismo, entendido como la doctrina que sostiene que los derechos de libertad son la condición necesaria (si bien no suficiente) de toda posible democracia. Para este autor, el avance del proceso de democratización al que hoy asistimos se refiere especificamente a "las democracias, guste o no guste, liberales" (Bobbio, 1989a, p. 2). Con todo, el problema de las relaciones entre liberalismo y democracia está muy lejos de ser evidente o sencillo. A veces parecería que Bobbio sostiene que se trata de una relación de necesidad lógica: no hay democracia sin liberalismo; otras, parecería que se trata de una relación contingente, es decir, de una relación posible bajo ciertas condiciones, ${ }^{1}$ en virtud de lo cual la democracia estaría necesariamente vinculada al liberalismo únicamente en las condiciones de desarrollo generadas por la sociedad moderna. En lo que sigue intentaré precisar las posibilidades de esa relación en la obra de Bobbio, con base en los principios qué subyacen en el liberalismo y la democracia; sólo de manera lateral se abordará la relación histórica que de hecho se ha dado entre ambos.

Antes de iniciar el análisis de esta compleja relación, es preciso hacer tres observaciones.

Una primera observación, de orden lingüístico, consiste en que las palabras "democracia" y "liberalismo" no pertenecen al mismo género. "Liberalismo", al igual que "socialismo", pertenece al género muy amplio de los ismos o de las ideologías, es decir, a un género que designa una doctrina articulada que comprende una visión general del mundo, a partir de la cual se construyen

1 Es la tesis de Bovero en "Liberalismo, socialismo, democrazia. Definizioni minime e relazioni possibili". 
modelos teóricos que pretenden interpretar la realidad, y un cierto modelo prescriptivo, mediante el cual se realizan ciertas opciones de valor y se marcan criterios relacionados con el deber ser o con la posibilidad de un cierto modo de ser del mundo (Bovero, 1990, p. 5). "Democracia", por su parte, no se refiere a una ideología específica diferenciable de otras, sino que pertenece al género de las cracias, al género de las formas de gobierno: es un concepto que alude a formas y mecanismos reguladores del ejercicio del poder político.

La segunda observación es extrínseca a la relación entre ambos términos: "democracia" es una palabra antigua, mientras que "liberalismo" es relativamente nueva. Si bien la democracia, como forma de gobierno, ha sufrido transformaciones para adaptarse a nuevas circunstancias históricas, a cambios sociales, a demandas exigidas por su extensión (Bobbio, 1989a, p. 6) aunque, según Bobbio, hoy no puede disociarse del liberalismo, el término ha conservado desde siempre un significado fundamental: la democracia se define como el gobierno de muchos o de la mayoría, es el gobierno del pueblo. El término "pueblo", sin embargo, es confuso y con frecuencia está cargado de un significado negativo. Por ello, cuando se concibe a la democracia como una forma de gobierno que indica el poder de un cuerpo colectivo -el demos, el pueblo-, esta noción se convierte en un obstáculo para la formación de un juicio positivo sobre aquélla. El "pueblo" no debe entenderse como sinónimo de la masa o como un cuerpo colectivo que "decide" como un todo: los que participan en la toma de las decisiones colectivas son los individuos particulares, cada uno de los cuales al ejercer este derecho cuenta por uno. Lo que ha cambiado de la democracia antigua a la moderna es la manera, amplia o restringida, en la que el titular del poder — siempre "el pueblo", entendido como conjunto de individuos, de ciudadanos, cada uno con sus intereses propiosejerce ese derecho, y el valor que se le ha dado al gobierno del pueblo, prefiriéndolo o no al gobierno de uno o de unos cuantos. ${ }^{2}$ Aun cuando la manera en que el pueblo ejerce el derecho de gobernar haya cambiado a lo largo de los siglos, no puede afirmarse que el significado antiguo de democracia no tenga nada que ver con la democracia moderna, cuyos conceptos medulares, bajo la interpretación de Bobbio - una cierta igualdad y una cierta libertadson los mismos que encontramos en la concepción griega de la democracia.

El liberalismo, por el contrario, es una corriente de ideas que surge en la Edad Moderna. Como sistema coherente de ideales y metas prácticas, el li-

2 En su artículo "La democrazia dei moderni paragonata a quella degli antichi (c a quella dei posteri)", Bobbio señala la equivocidad que encierran tanto la noción de "pueblo", como la de "soberanía popular", sobre la cual se pretende fundar la democracia moderna. "La soberanía -escribe Bobbio- no es del pueblo sino de los individuos particulares, en tanto que ciudadanos. [... E En la democracia moderna el soberano no es el pueblo sino todos los ciudadanos. El pueblo es una abstracción, cómoda pero también, como he dicho, falaz; los individuos, con sus defectos $y$ con sus intereses, son una realidad" (pp. 10-11). 
beralismo tiene sus orígenes en Inglaterra durante los siglos XVII y XVIII, en particular en el pensamiento y la política ligados a la revolución inglesa de 1688, cuya justificación clásica es la filosofía política de John Locke. El constitucionalismo, la tolerancia religiosa y la actividad comercial que fomentó esta "revolución gloriosa" se convirtieron en un modelo para los liberales europeos y americanos del siglo XVIII. A partir de entonces, de manera independiente o derivada del modelo inglés, se expande en Europa y en otros lugares del mundo, presentándose en los distintos países en tiempos históricos diversos, lo cual impide hablar de una historia del liberalismo como si fuera un fenómeno unitario y homogéneo. Este hecho, aunado a la dificultad de establecer un consenso sobre lo que hay de liberalismo y lo que hay de democrático en las actuales democracias liberales, dada la estrecha relación que existe entre la historia del liberalismo y la de la democracia moderna, dificultan la posibilidad de dar una definición precisa del liberalismo.

Parecería, entonces, que el liberalismo no puede definirse como un conjunto de valores políticos y morales inmutables, en tanto que como movimiento histórico de ideas ha sufrido muchos cambios desde sus inicios, que han dado lugar a distintos grupos de posiciones políticas llamados todos liberales, aun cuando tales grupos parecen no compartir los mismos principios fundamentales. El liberalismo no sólo ha aparecido en diversas formas y en diferentes épocas y lugares, sino que, al igual que otras corrientes de pensamiento, ha estado dividido internamente y por lo tanto se resiste a una definición precisa. No obstante, sin pensar en los cambios y el desarrollo como meramente marginales o superficiales, hay ciertas continuidades, ciertos hilos comunes, que corren a lo largo de la historia del liberalismo. En el plano institucional, esta doctrina consiste en la búsqueda de mecanismos constitucionales para limitar el poder del Estado y garantizar la libertad, o ciertas libertades, de los individuos. El liberalismo no sólo es, entonces, una reivindicación de la libertad, o de ciertas libertades, como valor supremo, sino "la búsqueda de garantías y tutela jurídico-política para estos valores” (Bovero, 1990, p. 7). La doctrina del Estado liberal es "la doctrina de los límites jurídicos del poder estatal" (Bobbio, 1985, p. 16). En el plano ético-político, una constante de esta doctrina política es la defensa del principio de la libertad del individuo contra el poder (estatal o eclesiástico) si éste impide el libre desarrollo de su personalidad. Así, uno de los significados fundamentales del liberalismo consiste, a partir de la convicción de que el hombre es libre, en el rechazo de todo aquello mediante lo cual una autoridad exterior, cualquiera que sea su origen o su finalidad, pretenda paralizar o impedir las determinaciones individuales. La manifestación jurídica de esta defensa de la libertad del individuo y de la búsqueda de garantías son las distintas cartas y declaraciones de los derechos del hombre y las maneras, más o menos eficaces, para su tutela jurídica. 
Una tercera observación se refiere a la relación entre los valores a partir de los cuales una determinada teoría elabora distintas concepciones de mundos posibles. Una teoría desarrollada, como es el liberalismo, no pone sus valores en el mismo nivel, sino que les otorga un orden de preferencia. El peso relativo que se da a cada uno de ellos en relación con los otros es lo que permite distinguir una posición política de otra. Así, por ejemplo, como muestra Dworkin en su ensayo sobre el liberalismo, "el liberalismo comparte los mismos principios constituyentes de muchas otras teorías políticas, entre ellas el conservatismo, pero se distingue en que concede una importancia relativa diferente a distintos principios" (Dworkin, 1978, p. 123). ${ }^{3}$ Limitarse a decir, por ejemplo, que el socialismo se define por la igualdad, mientras que la libertad es lo que define al liberalismo, aun cuando se esté señalando el punto de partida de cualquier análisis, únicamente nos ofrecería una definición no sólo general y abstracta, sino equivocada, de estas dos doctrinas. Para evitar las definiciones ambiguas o demasiado genéricas, habría que responder en qué sentido la libertad es prioritaria para el liberalismo y cuáles son las libertades que forman el contenido mínimo de la doctrina liberal, así como qué implica para el socialismo que la igualdad sea el valor fundamental, de qué igualdad se trata y en qué medida se considera que debe ser aplicada.

¿Qué tanto pueden combinarse el liberalismo y la democracia? ¿Cuáles son las características o los principios fundamentaies de uno y otro que permiten la relación entre una forma de gobierno, caracterizada por una cierta distribución del poder y por ciertos procedimientos específicos, y una ideología política que concibe la realidad de una cierta manera y prescribe la opción de ciertos valores?

Bobbio señala tres concepciones posibles o tres maneras posibles de ver la combinación entre liberalismo y democracia: a) liberalismo vel democracia: puede darse uno u otro, o los dos, se trata de una relación de posibilidad, donde liberalismo y democracia son compatibles, pueden convivir o darse de manera independiente; b) liberalismo aut democracia: no pueden estar juntos, son incompatibles, se trata de una relación de imposibilidad;

3 Por ello, la diferencia entre radicales, liberales y conservadores puede medirse en términos de la importancia que cada uno le otorgue a la igualdad y a la libertad. Mientras el radical se interesa más por la igualdad y menos por la libertad que el liberal, el conservador tiende a propiciar mucho menos la igualdad: "El liberal -escribe Dworkin- viene a ser el centro, lo que explica por qué tan frecuentemente se considera hoy que el liberalismo es blandengue y un compromiso indefendible con dos posiciones más francas" (Dworkin, 1978, p. 123). Asimismo, las distintas posiciones que han surgido dentro de la misma doctrina liberal a lo largo de su historia serían, en parte, una consecuencia de las diversas tendencias que favorecen más la libertad o la igualdad. 
c) liberalismo et democracia: están necesariamente unidos, es una relación de necesidad, el uno no puede estar sin el otro (Bobbio, 1985, p. 59). Los análisis de Bobbio sobre las relaciones entre liberalismo y democracia tienden a inscribirse en la primera de estas combinaciones: se trataría, para él, fundamentalmente de una relación de posibilidad, tanto desde el punto de vista histórico, ya que aun cuando se trata de una relación que de hecho se ha dado, ha sido bajo ciertas condiciones concretas (las de la sociedad moderna), como desde el punto de vista lógico, ya que su compatibilidad depende del modo como se entiendan o se definan los principios del liberalismo y de la democracia. ${ }^{4}$ En realidad la contribución teórica más novedosa de Bobbio tiene que ver con la posibilidad de la relación entre socialismo y liberalismo, esto es, con la posibilidad de elaborar una teoría socialista liberal, donde coexistan la defensa de las libertades civiles y políticas del liberalismo y el principio de la justicia social del socialismo. En este trabajo únicamente trataremos de analizar la posibles combinaciones entre liberalismo y democracia, a partir de los dos principios aparentemente compartidos por ambas posiciones: la libertad y la igualdad.

\section{III}

Cuando decimos que los liberales creen en el valor de la libertad y se proclaman sus defensores, ¿de qué libertad estamos hablando?, ¿libertad de qué? ¿Existe alguna diferencia entre la libertad defendida por los liberales y la libertad entendida como uno de los fundamentos de la democracia? La respuesta a esa pregunta contiene la clave de inteligibilidad de cualquier tipo de liberalismo y de sus posibles relaciones con la democracia y con el socialismo, además de que es una prueba de que la discusión en torno a esta corriente política es algo más que un mero ejercicio académico: es una cuestión política actual.

En el lenguaje político, el concepto de libertad tiene dos significados fundamentales: la libertad como no interferencia, como facultad de realizar ciertas acciones o no sin ser obligado o detenido por los demás, por la sociedad o por el poder estatal, y la libertad como autonomía, como poder de no obedecer más normas que las que me he impuesto a mí mismo.

La libertad en el primer sentido es una constante en la teoría liberal clásica: los liberales buscarán gozar de una esfera de acción cada vez más amplia, no controlada por el poder estatal. El segundo sentido de libertad se emplea en

4 Como señalaba al principio, a veces parecería que Bobbio habla de una relación necesaria: se trataría de una "necesidad histórica", esto es, de una relación que surgió necesariamente dadas ciertas condiciones específicas - las de desarrollo de la sociedad moderna-; si bien Bobbio habla de la historia como vehículo de la "fuerza de las cosas", sería, en rigor, una relación contingente, posible bajo ciertas condiciones. 
la teoría democrática: para los demócratas "ser libre" no significa no tener leyes, sino darse leyes a sí mismo, por lo que tenderán a crear cada vez más órganos de autogobierno.

Benjamin Constant, buscando comprender por qué la Revolución francesa había degenerado en el "reino del terror" y criticando las bases conceptuales del concepto de libertad política como autonomía de Rousseau, hablaba de dos libertades: la libertad de los antiguos y la libertad de los modernos. Es bajo la forma de la relación entre estas dos libertades, o entre estas dos caras de la libertad, como comienza la historia de la contraposición teórica entre liberalismo, libertad de los modernos, y democracia, libertad de los antiguos (y de los contemporáneos).

En uno de sus significados, la libertad, que Constant llama la libertad de los modernos - la "libertad negativa" según el famoso artículo de I. Berlin (Berlin, 1969) - significa ausencia de impedimentos y de constreñimientos: "en tanto que los límites a nuestras acciones en la sociedad son impuestos por normas (consuetudinarias o legislativas, sociales o jurídicas o morales), la 'libertad negativa' consiste en hacer (o no hacer) todo aquello que las leyes, en sentido lato, y no sólo en sentido téenico-jurídico, permiten, o bien no prohiben (y en cuanto tales permiten no hacer)" (Bobbio, 1979, p. 994). El problema de la libertad aparece, en este primer sentido, como el de la exigencia de límites a la acción del estado. La libertad negativa, es decir, la libertad identificada con la no obstrucción, asignada a los estados modernos, es el derecho de no estar sometido más que a las leyes y nunca a la voluntad arbitraria de uno o de varios individuos, es el derecho de gozar de ciertas libertades personales tales como la libertad de opinión, de iniciativa económica, de reunión, etcétera. El prototipo de la libertad negativa, libertad como "no interferencia" o libertad de los modernos, son las libertades civiles, es decir aquellas que son o deben ser protegidas por la ley. Como ejemplos pueden señalarse la libertad de expresión, de movimiento y de asociación.

Históricamente, estas libertades "son el producto de las luchas por la defensa del individuo considerado como persona moral, y por tanto poseyendo un valor en sí mismo, o como sujeto de relaciones económicas, contra la invasión de entes colectivos como la Iglesia o el Estado" (Bobbio, 1979, p. 996). Filosóficamente, el presupuesto de las libertades individuales y la justificación de los límites del poder del Estado es la doctrina de los derechos del hombre, elaborada por la corriente iusnaturalista, según la cual todos los hombres tienen por el simple hecho de serlo, y no en virtud de algún acuerdo o sistema de leyes especial, ciertos derechos fundamentales-naturales que el Estado tiene la obligación de respetar y garantizar. Para los iusnaturalistas, entre los derechos "naturales" hay algunos de los que no pueden disponer los hombres 
sin negar su propia identidad, ${ }^{5}$ mientras que hay otros de los que pueden desprenderse, sólo voluntariamente, con el fin de crear, junto con los demás individuos, una sociedad, un cuerpo artificial. Es decir, el Estado sería antes una creación mecánica y artificial del hombre que un cuerpo político orgánico e histórico, cuyo objetivo sería el de proteger mejor aquellos derechos inalienables. El Estado, según el iusnaturalismo, sería el "resultado de un acuerdo entre individuos en principio libres que convienen en establecer los vínculos estrictamente necesarios para una convivencia duradera y pacífica" (Bobbio, 1985 , p. 14).

Tres consecuencias básicas para la doctrina liberal se desprenden de la teoría de los derechos naturales: a) mantener que la fuente última de toda autoridad gubernamental reside en los individuos, en tanto que poseen iguales derechos naturales y sólo voluntariamente pueden colocarse bajo la autoridad política de otro; b) la función primera de todo gobierno es el mantenimiento y protección de los derechos naturales; c) los derechos naturales establecen límites a la autoridad de los gobiernos. Tanto la teoría del contrato social, como la doctrina de los derechos naturales a la que se está vinculada, son una manifestación de la concepción individualista de la sociedad, es decir, de aquella según la cual el individuo siempre tiene prioridad sobre la sociedad, concepción que se encuentra en la base de la doctrina liberal (aun cuando no todo contractualismo sea liberal). ${ }^{6}$

Los derechos naturales individuales, anteriores a la formación del poder político, son derechos que describen, en el contexto político, los derechos mínimos que el gobierno debe proteger, asegurar y respetar, con lo que se marcan así ciertos límites a la extensión del poder estatal. El liberalismo clásico es, entonces, una determinada concepción del Estado, "la concepción según la cual el Estado tiene poderes y funciones limitados, y como tal se contrapone tanto al Estado absoluto como al Estado que hoy llamamos social” (Bob-

5 Según Locke, en cuyos escritos se encuentra la expresión más influyente de la teoría liberal de los derechos naturales, "nadie debe perjudicar a otro en su vida, salud libertad o propiedades". La enumeración de los derechos naturales varía en las distintas declaraciones de derechos naturales de los siglos XVIII y XIX, siendo superadas por la Declaración de los Derechos Humanos de las Naciones Unidas de 1948 y por las diversas declaraciones de los Acuerdos y Convenciones de la ONU que la siguieron. Con todo, cuáles son o deben ser los derechos fundamentales sigue siendo un problema teórico no fácil de zanjar.

6 Para Bobbio, si todavía tiene sentido discutir hoy día sobre el liberalismo, y si después de la decadencia y casi abandono total de las ideas liberales se puede hablar de un renacimiento de esta doctrina, tanto en la práctica como en la teoría, es justamente en virtud de la concepción individualista de la sociedad y de la historia en las que se basa: "el pensamiento liberal - escribecontinúa renaciendo, incluso bajo formas que pueden irritar por su carácter regresivo, y desde muchos puntos de vista ostentosamente reaccionario [... ] porque está basado en una concepción filosófica de la que, guste o no, nació el mundo moderno: la concepción individualista de la sociedad y de la historia” (Bobbio, 1984, p. 100). 
bio, 1985, p. 7). El Estado, con poder y funciones limitadas - de derecho y mínimo - se concibe, desde el punto de vista del individuo, como un "mal necesario" y por consiguiente debe intervenir lo menos posible en la vida de los individuos.

En la lucha contra el Estado absoluto, la doctrina liberal defiende el estado de derecho, es decir, un Estado donde no sólo los poderes públicos están subordinados a las leyes (estado de derecho en sentido débil o formal), sino que además las leyes están subordinadas a algunos derechos fundamentales considerados constitucionalmente, y por tanto en principio "inviolables" (estado de derecho en sentido profundo). Las libertades individuales quedan garantizadas, según el pensamiento liberal, únicamente en un estado de derecho mediante ciertos mecanismos constitucionales que tienen como fin limitar los poderes del Estado, impidiendo el ejercicio arbitrario e ilegítimo del poder y dificultando el abuso o el ejercicio ilegal (cfr. Bobbio, 1985, p. 19).

Contra el estado máximo o el llamado estado social, el liberalismo es defensor del estado minimo, es decir, de un Estado cuyo ámbito de intervención sea limitado; las funciones del Estado deben limitarse al mínimo necesario para la supervivencia de la comunidad. Una vez más, el liberalismo defiende la primacía de la libertad del individuo frente al poder del Estado y, por ende, la subordinación de los deberes del Estado a los derechos o intereses del individuo ( $c f r$. Bobbio, 1985, p. 25). El Estado liberal se opone a cualquier tipo de Estado paternalista que se plantee como objetivo promover algo así como "la felicidad" general y considere que sus ciudadanos deben ser tratados como menores de edad. Este es el sentido de la crítica de Kant, por ejemplo, al Estado paternalista que busca establecer en qué debe consistir la felicidad de sus ciudadanos, cuando su único fin debería ser el de impedir que el logro de los fines individuales sea conflictivo.

En la actualidad, algunas formulaciones del liberalismo como teoría de los límites del poder del Estado tienden a identificarse cada vez más con la doctrina del estado mínimo, es decir, un Estado cuya única función legítima consistiría en ser un "Estado vigilante", no intervencionista, sobre todo en la esfera de vida económica de los individuos. Contra los intentos del estado máximo - del llamado estado de bienestar o "estado de justicia” — por resolver, entre otros, el problema de la justicia social, el liberalismo, como teoría del estado minimo, se basa en una doctrina radical de los derechos individuales, en particular del derecho de propiedad, excluyendo los derechos a la asistencia social. ${ }^{7}$ Los partidarios de esta forma contemporánea del liberalismo sostienen no sólo que una de las tareas prioritarias del Estado es la tutela de

7 Por ejemplo, R. Nozick, en su libro Anarchy, State and Utopia, señala que el Estado no tiene poderes legítimos fuera de la esfera de las funciones de la protección, de la justicia y de la defensa nacional. Cualquier otra función requerinía constantes interferencias en la libertad individual. 
la propiedad privada, sino, además, que el sistema social más deseable sería un capitalismo laissez-faire, es decir, son defensores de una economía de libre mercado y de la libertad de iniciativa económica.

Por un lado, entonces, una vez que los derechos fundamentales son reconocidos y protegidos jurídicamente, el Estado liberal, a diferencia del Estado absoluto, tiene poderes limitados: esos derechos implican la delimitación de ciertas materias que se declaran indisponibles al derecho, como es el caso de los espacios de libertad en los que el poder estatal no puede intervenir. Por otro lado, el Estado liberal, en contraposición al Estado social, tiene funciones limsitadas en tanto que los fines del gobierno deben limitarse a asegurar las condiciones para la protección y garantía de los derechos fundamentales, sin invadir la esfera de libertad de los individuos. El sentido preponderante de la libertad para la doctrina liberal es, pues, la libertad frente al Estado (Bobbio, 1985, p. 23), la cual puede dividirse de manera esquemática en dos aspectos: las llamadas libertades civiles y las llamadas libertades económicas, encabezadas por el derecho de propiedad. ${ }^{8}$ El compromiso de Bobbio con el liberalismo es con el primer tipo de libertades y no con el aspecto económico del liberalismo, es decir, con el liberalismo como teoría económica, partidario de la economía de mercado, el llamado "liberismo".

La democracia es, en cambio, una forma de gobierno en la cual el poder está en manos de la mayoría, y su problema fundamental no es la limitación del poder, sino la distribución del pader. El problema es la exigencia de limitar cualquier forma de legislación impuesta desde arriba: se trata de la libertad de los antiguos, según Constant -la libertad positiva de I. Berlin-o la libertad entendida como autonomía o autodeterminación. Es el concepto de libertad defendido por Rousseau, quien identifica la libertad y la obediencia a las leyes que nos prescribimos nosotros mismos y, a su vez, la obediencia a la voluntad colectiva: la libertad coincide con la autodeterminación colectiva. Según Constant, esta forma de libertad, atribuida a las ciudades-estado de la Antigüedad, es la libertad de participar en el poder político: "El fin de los antiguos era la distribución del poder social entre todos los ciudadanos de una misma patria. Eso era lo que llamaban libertad. El fin de los modernos es la seguridad en los goces privados; y llaman libertad a las garantías acordadas por las instituciones a esos goces" (Constant, 1872, p. 539). En este sentido,

8 Sería necesario discutir si la relación entre los derechos fundamentales de libertad y la libertad de mercado es una relación de implicación, o si, por el contrario, es posible distinguir dos liberalismos, el liberalismo económico o liberismo y el liberalismo político. Una preocupación presente en los escritos de Bobbio es si la situación de mercado es imprescindible para que puedan darse las libertades individuales y el desarrollo de la libertad positiva. 
la libertad positiva - libertad política - en tanto que se traduce por la participación en la toma de las decisiones políticas: votación de las leyes, adopción de tratados, control de los magistrados, etc., está referida al individuo, no considerado como unidad aislada, sino como miembro de una colectividad - pueblo, comunidad, nación, grupo étnico, patria- en el momento en que esta colectividad debe tomar decisiones que conciernen a la sociedad en su conjunto, es decir, a todos los ciudadanos como tales. "Para la teoría política - escribe Bobbio- el problema históricamente relevante no es tanto el de la autodeterminación del individuo (problema teológico o filosófico o moral) como el de la autodeterminación del cuerpo social del cual forma parte el individuo" (Bobbio, 1979, p. 996).

El punto esencial consiste en determinar si la libertad política prolonga la independencia individual garantizándola o si más bien la absorbe. En la época moderna, los fines del liberalismo y los fines de la democracia aparecen como dos principios antagónicos: la demanda de los modernos de limitar el poder y la de los antiguos, de distribuirlo igualmente eran vistas por los liberales clásicos como tendencias hacia dos fines opuestos, incluso contradictorios: siendo la independencia individual el bien más preciado de los modernos, no había que pedirles su sacrificio a cambio de la libertad política. La participación directa de los ciudadanos en la toma de las decisiones colectivas, la dedicación a la vida pública, era posible para los individuos de la antigüedad, quienes vivían sólo como miembros de la ciudad y su vida privada se reducía a la vida familiar. Por el contrario, los individuos modernos persiguen sus intereses particulares mediante relaciones interindividuales, en el tejido de relaciones sociales que constituyen la sociedad civil; su participación en la vida colectiva absorbería su tiempo, limitando su esfera de libertad individual ( $c f r$. Bobbio, 1989, p. 8). Para los liberales, el ciudadano debe estar al servicio del hombre y no al revés. El Estado tendría como fin último el reconocimiento y la promoción de la libertad, mientras que la libertad política tendría un valor instrumental, sería un medio político para el logro más seguro de la libertad como no impedimento (democracia como protección).

Durante todo el siglo XIX el liberalismo y la democracia se desarrollan de manera independiente en una serie de encuentros y enfrentamientos: los liberales acusan a los demócratas de preparar el camino para un nuevo despotismo, en la medida en que suponen que la ampliación del sufragio implica una disminución de libertad, y los demócratas acusan a los liberales de defender, bajo la especie de libertad, el interés particular de los propietarios, lo cual da como resultado que los derechos, concebidos para ser los derechos del Hombre, de todo hombre, ya no son, en el Estado liberal, más que los derechos del individuo "posesivo". En verdad, la libertad económica tuvo consecuencias perversas, que no tuvieron las otras libertades, en la calidad de vida de los individuos; ello condujo, a partir de la conquista del sufragio universal, 
a favorecer una mayor intervención del Estado con el objeto de detener o minimizar los efectos del libre mercado, superando los límites dentro de los cuales la doctrina liberal consideraba que se debería restringir el Estado. Por eso Bobbio puede afirmar que "para los liberales de nuevo cuño el problema es el de salvar, si todavía es posible y por aquello que es todavía posible, a la democracia sin salir del capitalismo. Hoy les parece a estos nuevos liberales que la democracia es la que pone en crisis al capitalismo" (Bobbio, 1984, p. 98). ${ }^{9}$

¿En qué sentido o bajo qué condiciones pueden convivir, entonces, la democracia y el liberalismo? Si la libertad negativa se expresa sobre todo como ausencia de constreñimientos y la libertad positiva como posibilidad del individuo de participar en el ejercicio del poder político, los derechos políticos pueden llegar a considerarse como la garantía de la libertad negativa, en la medida en que si los individuos participan en el ejercicio del poder, no corren el riesgo de que se les impongan medidas arbitrarias que limiten sus libertades individuales. En otras palabras, podría suponerse que entre los derechos individuales y el poder político hay una garantía recíproca, aunque dicha implicación no ocurre de manera automática. Si la doble garantía subsiste, los derechos políticos (la libertad positiva) podrían presentarse como un agregado coherente de los derechos individuales y, como señala Bobbio, "si la libertad negativa es moderna, la libertad positiva, en lugar de ser antigua, es todavía más moderna" (Bobbio, 1979, p. 998). Para los modernos, la libertad negativa, las libertades individuales, se prolongan en la libertad política, por lo que el dualismo entre la libertad positiva y la libertad negativa no debería implicar su antinomia.

Es evidente que el Estado liberal no es necesariamente democrático (es posible un Estado liberal que no reconozca el sufragio universal) y que un gobierno democrático no genera forzosamente un Estado liberal (Bobbio, 1985, p. 7). Pero, también es cierto que en la historia del Estado moderno las dos libertades - la del liberalismo y la de la democracia - están estrechamente interconectadas; en un sentido, sin libertades civiles la participación popular en el poder político es un engaño, es decir, son necesarias ciertas libertades para asegurar el correcto ejercicio del poder democrático: "la participación en el voto puede ser considerada como el correcto y eficaz ejercicio de un poder político, es decir, del poder de influir en la toma de las decisiones colectivas, sólo si se realiza libremente, si el individuo que va a las urnas para sufragar goza de las libertades de opinión, prensa, reunión, asociación, es decir, todas

9 Partiendo del análisis del hecho histórico de que las democracias se han desarrollado fundamentalmente en sociedades capitalistas de mercado, Bobbio plantea los límites que el sistema económico capitalista le impone a la democracia y la necesidad de mostrar que no se trata de una conexión necesaria, sino que, por el contrario, sería deseable la compatibilidad de la democracia con otro tipo de sistema económico. 
las libertades que constituyen la esencia del Estado liberal y que en cuanto tales fungen como presupuestos necesarios para que la participación sea real y no ficticia” (Bobbio, 1985, p. 46). Y, en el otro sentido, sin participación popular en el poder, las libertades civiles tienen pocas probabilidades de durar, esto es, es indispensable el poder democrático para garantizar la existencia y la persistencia de las libertades fundamentales ( $c f$ r. Bobbio, 1979, p. 998; 1984, pp. XI-XII): los ideales liberales y el método democrático "gradualmente se han entrelazado de tal manera que, si es verdad que los derechos de libertad han sido desde el inicio la condición necesaria para la correcta aplicación de las reglas del juego democrático, también es verdad que sucesivamente el desarrollo de la democracia se ha vuelto el instrumento principal de la defensa de los derechos de libertad" (Bobbio, 1985, p. 48).

La definición formal, de procedimiento, que Bobbio da para democracia, queda integrada a la tradición liberal de los derechos fundamentales de libertad y vinculada a la noción de Estado de derecho: “podemos definir la democracia como aquel régimen que permite tomar decisiones con el máximo consenso de los ciudadanos, fundado sobre los principios de libertad, de modo que los ciudadanos puedan elegir a sus gobernantes, y, al mismo tiempo, fundado sobre el principio del Estado de derecho que es lo que obliga a los gobernantes a no volver exorbitante su poder y a ejercerlo en el ámbito de un sistema de normas escritas" (Bobbio, 1986, p. 45).

En cuanto a la libertad, resulta así que, una vez determinados los dos significados de libertad en el lenguaje político, la libertad liberal y la libertad democrática no sólo no son incompatibles, sino que además de que su relación es posible, pueden reforzarse una a la otra: "la evolución del Estado representativo moderno se ha caracterizado por una lucha ininterrumpida, con subidas y caídas, en favor de la ampliación de las libertades civiles y de la libertad política” (Bobbio, 1979, p. 998). En la historia real, el Estado democrático termina siendo la continuación necesaria, inevitable, del Estado liberal, en el sentido de que sólo con el Estado democrático pueden seguir siendo liberales los Estados liberales.

¿Qué sucede en cuanto a la igualdad? Hay una tendencia a considerar libertad e igualdad como dos valores antitéticos, o que por lo menos suelen entrar en conflicto, en tanto que la realización plena de uno de ellos parecería limitar fuertemente la realización del otro. ${ }^{10}$ Mientras que la libertad sería un valor para el hombre en tanto que individuo, la igualdad sería un valor

10 Este es un primer acercamiento al tema de la igualdad y de su relación con la libertad que no agota de ninguna manera el complejo problema de por qué y de qué manera ciertos tipos de igualdad pueden convertirse en una amenaza para ciertos tipos de libertad. 
para el hombre en tanto que ser social. Según esto, la doctrina liberal tendería a buscar un tipo de igualdad que respetara la diversidad, mientras que las doctrinas políticas defensoras de la igualdad en general buscarian un tipo de igualdad que eliminara las diferencias. ${ }^{11}$ Sin embargo, ello no implica que la igualdad sea un valor sin importancia para los liberales: "puede mostrarse que una concepción particular de la igualdad es constituyente del núcleo de posiciones centrales del liberalismo" (Dworkin, 1978, p. 122).

Al igual que con la libertad, para Bobbio cualquier discusión política sobre la igualdad se vuelve inútil si no se especifica de qué igualdad se trata, respondiendo, en este caso, dos preguntas básicas: a) igualdad entre quiénes, b) igualdad en qué. Una doctrina igualitaria podría definirse como aquella que responde estas preguntas exigiendo -en el límite ideal — la igualdad de todos en todo, es decir, una doctrina que tiende a buscar la igualdad del mayor número de individuos en el mayor número de cosas. La doctrina liberal no tiene nada que ver con una concepción igualitaria de la sociedad, en tanto que sólo pide la igualdad de todos en alguna cosa. La única forma de que la igualdad no sea incompatible con la libertad de la doctrina liberal es entenderla como igualdad en la libertad, en la cual se inspiran dos principios fundamentales del Estado liberal: la igualdad ante la ley (la protección igual de las leyes generales) y la igualdad de derechos (todos los hombres en cuanto tales poseen derechos iguales e inalienables). La función del Estado es la de garantizar que todos los individuos sean igualmente libres en este sentido.

Sin embargo, los teóricos llamados liberales discrepan sobre qué debe entenderse por igual libertad. Los partidarios del estado mínimo identifican la libertad igual con el derecho casi absoluto a poseer propiedades y a establecer contratos, sin tener en cuenta la distribución de recursos que implica este derecho. Para Nozick, por ejemplo, la condición de libertad igual no supone, más bien excluye, la distribución de los recursos disponibles según las necesidades. Según Rawls, el fin de la justicia social es maximizar el valor de la libertad para los miembros menos favorecidos de la sociedad, redistribuyendo si fuera necesario, las rentas y la riqueza de los ricos y propietarios entre los ciudadanos pobres y desposeídos de propiedad. Para Dworkin, el principio fundamental de la concepción de igualdad que es constituyente del liberalismo consiste en "pedir que el gobierno trate a todos los que están bajo su cargo como iguaLes, o sea, con el mismo derecho a su igual respeto y consideración”, bajo el supuesto fundamental de que el gobierno debe ser neutral respecto de lo que

11 Sin entrar en el difícil problema de intentar definir el socialismo, con respecto al cual parecería haber cada vez menos acuerdo sobre lo que es, habría que aclarar por lo menos que el principio de igualdad defendido por el socialismo no tiene nada que ver con la homogeneización de la sociedad: políticamente nunca se ha planteado una igualdad en todo, sino, más bien, la eliminación de ciertas formas de opresión que se basan en cierto tipo de desigualdad sobre todo económica. 
se llama la cuestión de la "buena vida", es decir, las decisiones políticas deben ser independientes de cualquier concepción particular de la buena vida o de lo que da valor a la vida (cfr. Dworkin, 1978, p. 127).

A pesar de las diferencias con respecto a la igualdad, el liberalismo, en general, es partidario de la igualdad entendida únicamente como igualdad ante la ley e igualdad de derechos $o$, a lo más, como igualdad de oportunidades, siempre y cuando ello no disminuya la esfera de libertad de los individuos. Llevada a sus últimas consecuencias, la igualdad de oportunidades deteriora la libertad humana al impedir a las personas desarrollar libremente sus recursos, sus aptitudes y sus virtudes para obtener resultados desiguales. Para los liberales, las personas deben ser libres para perseguir sus propios objetivos, incluso si ello entra en conflicto con la igualdad radical de oportunidades. El liberalismo supone que los ciudadanos de una sociedad tienen concepciones distintas, las cuales no deben convertirlos en más o menos iguales ante el gobierno: "propondría llamar liberal -escribe Bobbio- al que tiende a poner en evidencia no lo que los hombres tienen en común, en tanto que hombres, sino aquello que tienen de distinto, en tanto que individuos (de donde la frecuente reducción del liberalismo al individualismo)" (Bobbio, 1981, p. 28).

Para la democracia, la igualdad se define, fundamentalmente, como igualdad de poder político, es decir, como la igual oportunidad de los ciudadanos de participar en el gobierno de su sociedad, en tanto que son iguales respecto a la política: siendo iguales ante la ley, todos los individuos son igualmente dignos de gobernar y de tomar decisiones que afectan a la sociedad de la cual son miembros. La igualdad política, para los demócratas, se realiza con el sufragio universal.

Las dudas y las ambigüedades del liberalismo frente a la democracia aparecen con mayor fuerza en la manera como cada uno interpreta la cuestión de la igualdad. Cuando la preocupación de la democracia por la distribución igual del poder no se detiene en el poder político, liberalismo y democracia tienden a ser incompatibles. La raíz de la incompatibilidad entre liberalismo y democracia se encuentra en la tendencia a entender por democracia no sólo un mecanismo para elegir o autorizar gobiernos, promulgar leyes y adoptar decisiones políticas (democracia política), sino también un tipo de sociedad caracterizada por la igualdad social (respeto igual sin distinción de rango y status), y una cierta igualdad económica (aunque esta exigencia debe situarse estrictamente en el contexto del socialismo), lo cual supone una igualdad más que política (democracia social).

Bobbio no abandona en ningún momento su definición formal, minima y de procedimiento de democracia, y rechaza el concepto equívoco de "democracia 
social", entendido como asunto de igualdad o justicia social, pero que no tiene que ver con el sentido estricto de democracia, es decir, con el problema de quién decide y cómo se decide. Sin embargo, ello no significa que en sus escritos no encontremos, junto con la defensa de las libertades liberales y de la democracia formal, una seria preocupación por la igualdad y la justicia. En el tratamiento de estas cuestiones, hay una oscilación entre considerarlas como demandas exclusivas del socialismo o bien convertirlas en demandas de la democracia liberal. Una muestra de esta tendencia la encontramos en sus análisis sobre la relación entre igualdad y libertad, donde ya no aparece con tanta claridad su apuesta en favor de la prioridad de la libertad sobre la igualdad. $^{12}$

El desarrollo histórico de la democracia nos muestra que, a través de la lucha por la democracia, es decir, de la lucha por la igualdad en el poder político, pasó la demanda por otros tipos de igualdad, fundamentalmente la igualdad social y la igualdad económica. Para cumplir con sus principios de igualdad y libertad, en la medida en que a mayor igualdad con respecto al poder, mayor libertad, el ideal de igualdad de la democracia "se extiende hasta perseguir el ideal de cierta equiparación económica, ajena a la tradición del pensamiento liberal” (Bobbio, 1985, p. 45 y cfr. Bobbio, 1981, p. 30): sólo así puede llegar a garantizarse que todos sean igualmente libres. Aun cuando las demandas democráticas por una mayor igualdad, con respecto al poder político o al poder económico, no se confundan con el igualitarismo, esto es, con una sociedad en la que todos sean iguales en todo, sofocando el pluralismo, el liberalismo tiende a ser incompatible con la democracia cuando la definición de ésta pretende ir más allá de su concepción como una forma de gobierno. El Estado limitado defendido por los liberales, el Estado de derecho que deriva del supuesto de los derechos individuales, y que da lugar al Estado constitucional, es compatible con el método democrático; mientras que la defensa de la limitación de las funciones del Estado, del Estado mínimo, favorable a la economía de mercado y a la libertad económica, es incompatible - en ciertas circunstancias- con el ideal de mayor igualdad de la democracia. Así, el liberalismo es compatible con la democracia "a condición de que no se considere la democracia desde el punto de vista de su ideal igualitario, sino desde el punto de vista de su fórmula política: la soberanía popular” (Bobbio, 1985, p. 45).

Pero Bobbio no se detiene allí. Si liberalismo y democracia llegan a ser incompatibles en este aspecto, es porque la democracia, que puede definirse como la "forma de gobierno en la que todos son libres en tanto que son iguales" (Bobbio, 1981, p. 31), al buscar la igualdad de poder para todos tiende a acrecentar la libertad, pues el modo como está distribuido el poder

12 Por ejemplo, Bobbio, 1977 y Bobbio, 1981. 
en una sociedad contribuye a la mayor o menor libertad de sus miembros: "mientras que no tendría ningún sentido decir —escribe Bobbio- que sin libertad no hay igualdad, es perfectamente legítimo decir que sin igualdad (con respecto del poder recíproco) no hay libertad" (Bobbio, 1981, p. 29).

\section{VII}

El conflicto entre liberalismo y democracia es continuo y no se resolverá jamás de manera definitiva. Su alianza sólo puede ser resultado de negociaciones en favor de una y otra de sus demandas: limitar el poder y las funciones del Estado, en favor de un Estado mínimo, o distribuir el poder político. Pero, en contra de un poder sin límites, que niega o limita las libertades individuales, o en contra de un poder sin control que niega cualquier tipo de participación en la toma de las decisiones colectivas, liberalismo y democracia "se transforman necesariamente de hermanos enemigos en aliados" (Bobbio, 1985, p. 109).

No puede dejar de mencionarse que el contraste entre liberalismo y democracia se vio opacado, a partir de la segunda mitad del siglo pasado, por el contraste entre la liberal-democracia y el socialismo. Sin embargo, si en la unión entre liberalismo y democracia, la serie de las libertades individuales fue completada con la libertad política, por medio de la extensión del sufragio universal que otorga a todos los ciudadanos el derecho de participar en la formación de las decisiones colectivas que los atañen, en la unión entre democracia y socialismo se deberá pasar de la protección de los derechos de libertad a la protección de los derechos sociales, considerados no como un mero agregado a la lista anterior de derechos, sino como condición misma de su ejercicio efectivo. En este sentido, si la democracia es el perfeccionamiento del liberalismo, el socialismo sería el perfeccionamiento de la democracia. Pero, si el socialismo "real", que buscaba una sociedad libre y justa negó, a pesar de ello, los derechos de libertad que constituyen el presupuesto de la democracia liberal, después de la catástrofe del comunismo histórico, el gran desafío para la democracia en la actualidad consiste en poder responder, sin abandonar los derechos de libertad, “icon qué medios y con qué ideales se dispone a enfrentar los mismos problemas de los cuales nació el desafío comunista?” (Bobbio, 1990, p. 130). De ahí el intento de Bobbio por conciliar los ideales del liberalismo con los del socialismo, volviendo a proponer como lema de nuestro tiempo el de "Justicia y Libertad". 


\section{BIBLIOGRAFIA}

Arblaster, A., 1984, The Rise and Decline of Western Liberalism, Basil Blackwell, Londres.

Berlin, I., 1969, "Two Concepts of Liberty", en Four Essays on Liberty, Oxford University Press.

Bobbio, N., 1976, "Eguaglianza ed igualitarismo", Rivista Internazionale di Filosofia del Diritto, año LIII, fasc. 3.

—, 1977, "Eguaglianza”, en Enciclopedia del Novecento, Istituto dell'Enciclopedia Italiana, Roma, vol. II.

_-, 1979, “Libertà", en Enciclopedia del Nopecento, Istituto dell'Enciclopedia Italiana, Roma, vol. III.

- 1981, Le idcologic e il potere in crisi. Pluralismo, democrazia, socialismo, comunismo. Terza dia e terza forza, Felice le Monnier, Florencia.

—, 1984, Il futuro de la democrazia, Einaudi, Turín.

_ , 1984a, "Liberalismo vecchio e nuovo", en Il futuro de la democrazia, Einaudi, Turín.

_- 1985, Liberalismo y democracia, FCE, México, 1989.

- - 1986, Fundamento y futuro de la democracia, Edeval, Valparaíso.

$\longrightarrow, 1987$, "La democrazia dei moderni paragonata a quella degli antichi e a quella dei posteri”, Teoria Politica, vol. III, no. 3.

—, 1989, "Questioni di democrazia", en Sisifo 17.

- , 1990, "Lutopia capovolta", en L'utopia capopolta, Turín.

Bovero, M., 1990, “Quale liberalismo?”, mimeografiado.

_ 1991a, "Liberalismo, socialismo, democrazia. Definizioni minime e relazioni possibili", mimeografiado.

- 1991b, "La filosofia politica di Ferrajoli", mimeografiado.

Burdeau, G., 1979, Le libéralisme, Seuil, París.

Constant, B., 1872, "De la liberté des Anciens comparée à celle des Modernes", en Cours de politique constitutionnelle, t. II.

Dworkin, R., 1978, "Liberalism", en S. Hampshire, Public and Private Morality, Cambridge University Press.

Locke, J., 1689, Two Treatises of Government, P. Laslett (comp.), Nueva York, Mentor, 1965.

Matteucci, N., 1982, "Liberalismo", en N. Bobbio y N. Matteucci, Diccionario de Politica, L-Z, Siglo XXI, México. 